\title{
- Pentalogy of Cantrell: A Rare Case Report
}

\section{Soumya Jain ${ }^{1}$, Akhita Singhania' ${ }^{2}$, Rajasbala P Dhande ${ }^{3}$, Ayushi Jain ${ }^{4}$}

\section{IJCRR}

Section: Healthcare

ISI Impact Factor

(2019-20): 1.628

IC Value (2019): 90.81 SJIF (2020) $=7.893$
Junior Resident, Department of Radio-Diagnosis, Dmims, Wardha Maharashtra 442001, India; ${ }^{2}$ Senior Resident, Department of RadioDiagnosis, Dmims, Wardha Maharashtra 442001, India; ${ }^{3 H O D}$ and Professor, Department of Radio-Diagnosis, Dmims, Wardha Maharashtra 442001, India; ${ }^{4}$ Ramkinkar Hospital, Raipur Chattisgarh 492001, India.

(ब) (1) 8

Copyright@IJCRR

\section{ABSTRACT}

Introduction: Pentalogy of Cantrell is a rare, congenital disorder characterized by lower sternal defects, diaphragmatic defect, pericardial defect, supraumbilical abdominal wall abnormalities, and/or intracardiac defects. The collective defects result from the failure of either differentiation or migration of mesenchymal or mesodermal structures during the embryonic phase of development. Mortality of the disease complex is high, and treatment, when appropriate, revolves around the surgical correction of the associated defects.

Objective: This article presents a case of pentalogy of Cantrell and examines the literature to report the most current evidence relative to embryology and pathophysiology.

Methods: Case report was gathered from the OPD medical records and is provided as it occurred. The literature was searched for evidence of best management strategies as well as care implications for families.

Results: A newborn was delivered at 20 weeks' gestation secondary to termination of pregnancy. Prenatal ultrasonography identified an abdominal wall defect, diaphragmatic hernia, sternal defect, ventricular septal defect, kyphoscoliosis and club foot. Examination immediately after delivery confirmed prenatal findings and a diagnosis of pentalogy of Cantrell was assigned.

Conclusion: Pentalogy of Cantrell is a syndrome inclusive of five anomalies: a midline, upper abdominal wall disorder; lower sternal defect; anterior diaphragmatic defect; diaphragmatic pericardial defect, and congenital abnormalities of the heart. The pathogenesis of this condition is unclear, with associations being common and extremely challenging treatment. Prognosis and outcome of the condition depend on the type of pentalogy of Cantrell and the cardiac anomalies associated with it. Diagnosis can be made reliably by antenatal ultrasound during the first trimester. In this case report, we describe a fetus of undetermined sex who had the typical features of the very rare pentalogy of Cantrell. Patients with the diagnosis of pentalogy of Cantrell should receive antenatal counselling relative to mortality and morbidity risks. An interprofessional approach in the immediate timeframe after delivery facilitates timely diagnostics and offers families prompt confirmation of antenatal findings.

Keywords: Abdominal, Cardiac, Defect, Diaphragm, Pentalogy

\section{INTRODUCTION}

Thoraco-abdominal ectopia cord is or pentalogy of Cantrell ${ }^{1}$, is one of an extremely rare multiple congenital malformation syndrome and was first described in 1958 by James R. Cantrell et al. It comprises of the following five characteristics: a) midline, upper abdominal wall abnormality (e.g. omphalocele, gastroschisis), b) defect in the lower sternum (i.e. cleft sternum or absent sternum), c) anterior diaphragmatic defect (i.e. hypoplastic diaphragm, anterior diaphragmatic hernia), d) pericardial abnormality (e.g. ectopia cordis) and e) congenital abnormalities of the heart (e.g. tetralogy of
Fallot, ventricular septal defect, atrial septal defect). Complete pentalogy is very rarely found, with a frequency of approximately 1 incidence per 65,000-100, 000 live births and because of the different variants encountered, there are also less severe cases described in the literature.

Pentalogy of Cantrell has a very high mortality rate despite significant improvements in neonatal surgery. The prognosis for patients depends mostly on the severity of cardiac malformation with up to $95 \%$ mortality when ectopia cordis is present. $^{2}$

\section{Corresponding Author:}

Dr. Soumya Jain, Department of Radio-Diagnosis, Datta Meghe Institute of Medical Sciences (DU), Wardha Maharashtra- 442001, India. Email: soumya2403@gmail.com

ISSN: 2231-2196 (Print) ISSN: 0975-5241 (Online)

Received: $29.08 .2020 \quad$ Revised: 18.10 .2020

Accepted: 07.12 .2020

Published: 25.04 .2021 


\section{CASE REPORT}

Twenty-four-year-old, female, primigravida came for an anomaly scan at 20 weeks of gestation.

On ultrasound, there was a large anterior abdominal wall with herniation of liver, stomach and bowel loops outside the abdominal cavity suggesting omphalocele (figure 1), the heart was lying outside the thorax indicating ectopia cordis with associated lower sternal defect and ventricular septal defect (figure 2)

There was associated bilateral clubfoot and kyphoscoliosis of the spine (Figure 3 and 4)

There was also the presence of 2 vessel cord noted (Figure 5). The patient then underwent medical termination of pregnancy and gross specimen showed herniation of liver, stomach, bowel suggesting omphalocele and heart lying outside the thoracic cavity suggestive of ectopia cordis and associated bilateral club foot (Figure 6).
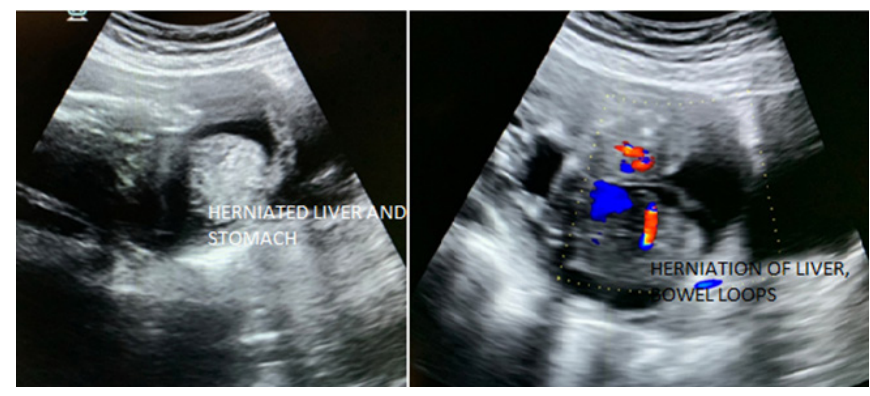

Figure 1: Transabdominal ultrasound, axial section of the abdomen showing herniation of the liver, stomach and bowel loops with Doppler flow.

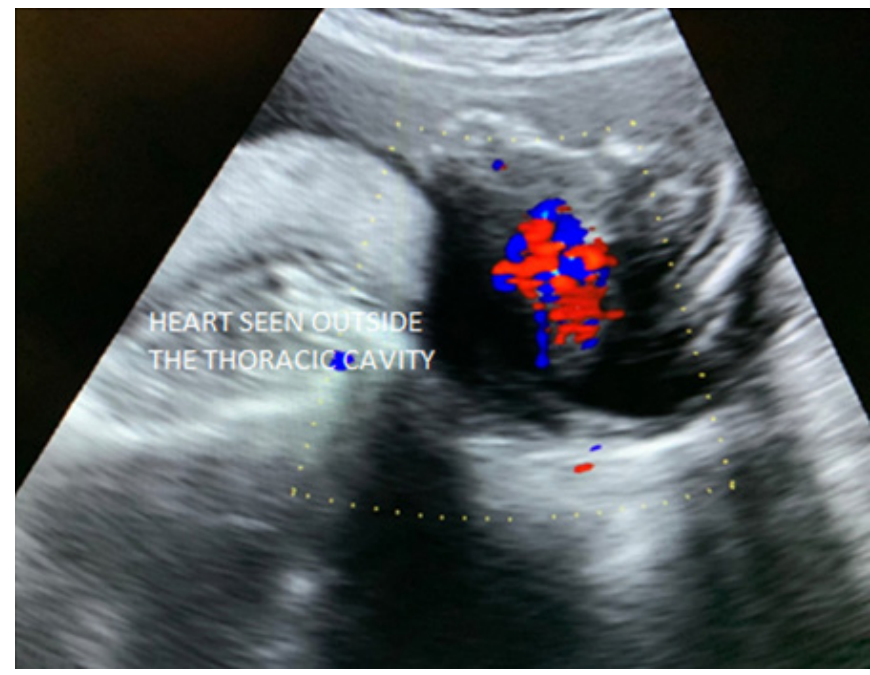

Figure 2: Transabdominal ultrasound showing heart outside the thoracic cavity.

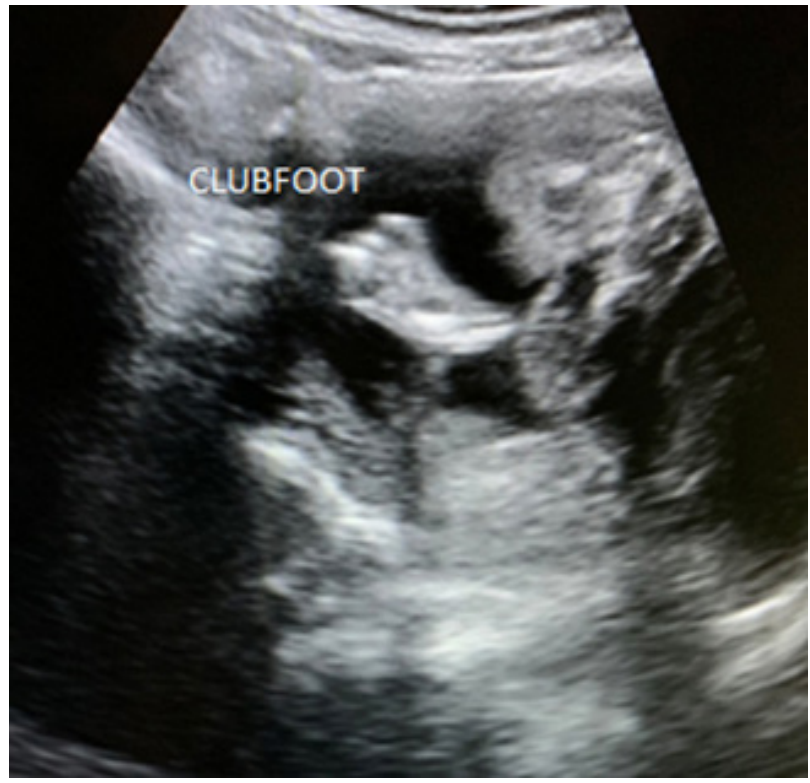

Figure 3: Transabdominal ultrasound showing club foot.

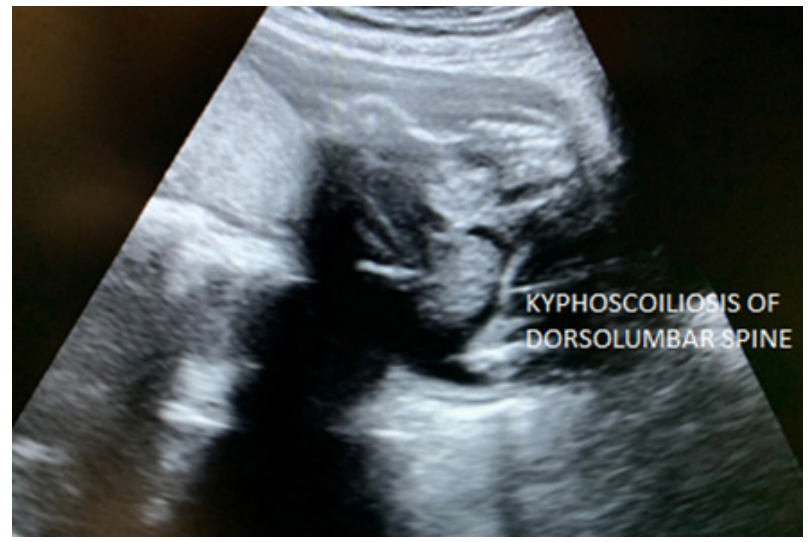

Figure 4: Transabdominal ultrasound showing kyphoscoliosis of dorsolumbar spine.

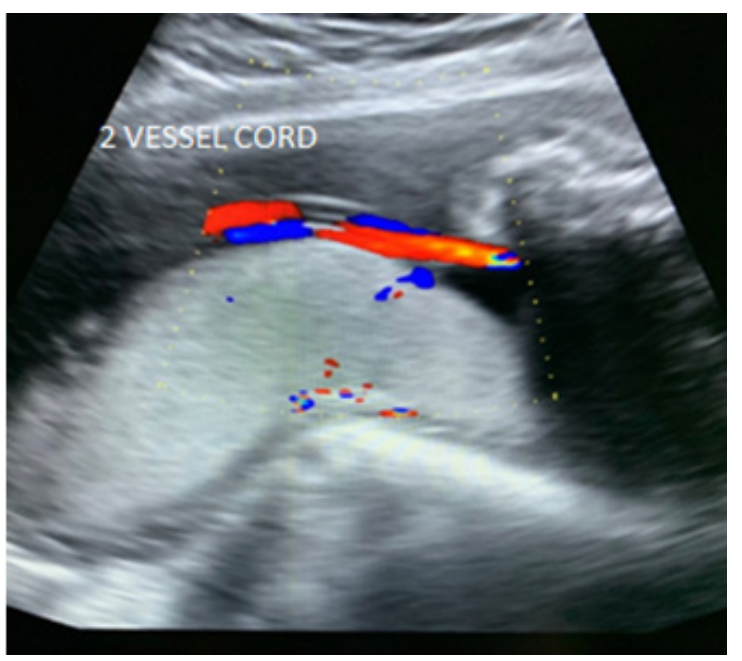

Figure 5: Transabdominal ultrasound showing 2 vessel cord. 


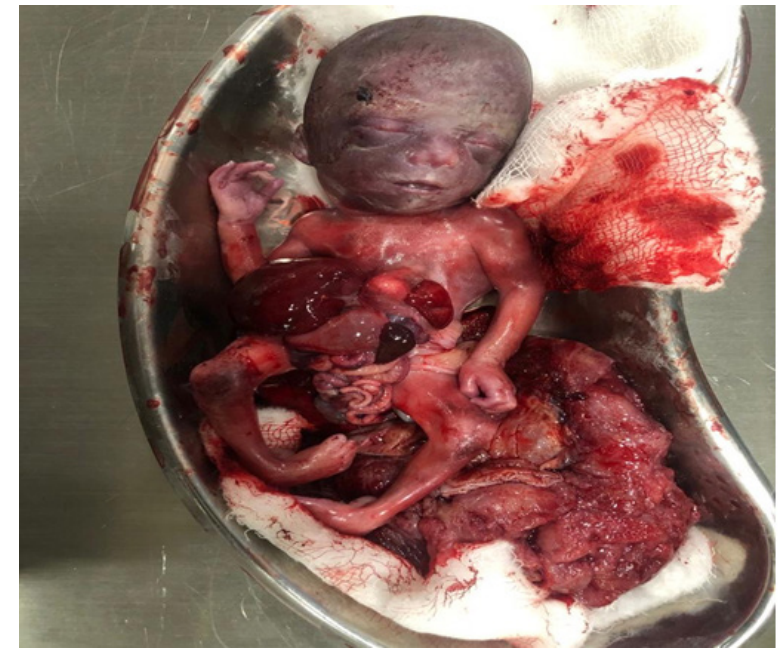

Figure 6: Gross specimen showing omphalocele, ectopia cordis and bilateral club foot.

\section{DISCUSSION}

Pentalogy of Cantrell (PC) is a deficiency of the anterior diaphragm, a midline supraumbilical abdominal wall defect, a diaphragmatic pericardium defect, congenital intracardiac abnormalities, and a defect of the lower sternum.

Incidence of the PC varies from 5.5 to 7.9 per million live births. The constellation of defects observed in PC is attributed to abnormalities in the intraembryonic mesoderm differentiation during embryogenesis at approximately 14 to 18 days after fertilization ${ }^{[2]}$. It is thought to result from abnormal migration of the sternal anlage and myotomes in the early 6 th to 7 th week of gestation, however, the exact pathology behind is still not clear. ${ }^{3}$

The diaphragmatic and pericardial defects result from abnormal development of the septum transversum, whereas the sternal and abdominal wall defects are most likely related to impaired migration of mesodermal structures. ${ }^{2}$ Pentalogy of Cantrell is a rare congenital anomaly, the pathogenesis of which has not been adequately elucidated.

Every case of PC may not necessarily present with all five originally described defects and thus have different variants with various degrees of severity, Toyama ${ }^{3}$ suggested a classification scheme for PC which consisted of three classes: Class I - certain diagnosis - includes cases with all five defects present; Class II - probable diagnosis - includes cases with four defects (with the presence of intracardiac and abdominal wall defects); Class III - incomplete diagnosis - includes cases with various combinations of defects (but with the presence of sternal defect). ${ }^{4}$ According to the above classification, Our case possibly belongs to Class II.

Familial cases have been described, suggesting probable recessive inheritance. There is one case report of PC with consanguineous parents. In our case, there was no consanguinity. $^{2}$

The pentalogy of Cantrell is often associated with ectopia cordis (EC) which also in itself is an extremely rare congenital heart defect characterized by complete or partial displacement of the heart outside the thoracic cavity. According to the heart location, there are four types of EC namely: cervical, cervicothoracic, thoracic and thoracoabdominal.

Intracardiac anomalies associated with the PC include ventricular septal defect (100\% of cases), atrial septal defect (around 53\% of cases), tetralogy of Fallot (around 20\% of cases), valvular or infundibular pulmonary stenosis (around $33 \%$ of cases), and ventricular diverticulum (around 20\% of cases). Other anomalies may be present alongside PC, these include the following: 1) asplenia described by Ludwiq et al. 2) tetralogy of Fallot, gallbladder agenesis and polysplenia described by Bittmann et al. ; 3) trisomy 18 - described by Hou et al. 4) central nervous system anomalies like craniorachischisis - described by Polat et al. 5)bilateral cleft lip and palate - described by Jafarian et al. ${ }^{4}$

With prenatal ultrasonography, the pentalogy of Cantrell can be diagnosed in the first trimester of pregnancy itself. Our case was reliably diagnosed antenatally despite the late presentation of the mother to the antenatal clinic at 20 weeks gestation. The visualization of fetal anomalies can be enhanced by the use of prenatal magnetic resonance imaging (MRI).

After birth, echocardiography is essential one of the essential investigations to be done for the diagnosis of associated cardiac anomalies. In our case, echocardiography was not done due to the refusal of all investigations by the parents. Conventional Radiography and sonography can be used to diagnose other features of the pentalogy of Cantrell and its associated anomalies. Unfortunately, small defects of the diaphragm and pericardium can be extremely difficult to diagnose accurately. In these patients and cases of possible surgical intervention, an MRI might be useful. Additional anomalies have been reported in some infants with pentalogy of Cantrell. Such anomalies include cleft lip, cleft palate, malformation (dysplasia) of the kidneys, a fluid-filled mass or sac in the head or neck area (cystic hygroma), limb defects (club feet, absent bones in the arms or legs) and birth defects of the brain and spinal cord (neural tube defects). ${ }^{5}$ Our case had a club foot and Scoliosis of the spine (deformity of the spine $)^{6}$ which are frequently described.

Treatment of PC is challenging, and the outcome depends on the size of the abdominal wall defects, ectopia cordis and other associated heart defects. The treatment consists of corrective or palliative cardiovascular surgery, correction of ventral hernia and diaphragmatic defects and correction of associated anomalies. ${ }^{2}$ 


\section{CONCLUSION}

In conclusion, the Pentalogy of Cantrell is a very rare constellation of congenital anomalies that can be reliably diagnosed antenatally and prognosis depends on the type of PC and associated cardiac anomalies. The parents should be given complete counsel on the understanding and prognosis of this condition.

\section{ACKNOWLEDGEMENT}

I acknowledge the immense help received from the scholars whose articles are cited and included about this article. I'm grateful to authors/editors/publishers of all those articles and journals from where the literature for this article has been reviewed and discussed.

Ethical Approval: The ethical committee of the Faculty of Medicine in Datta Meghe Institute of Medical Sciences (Deemed to be University )approved this case study. Informed consent was taken from the patient.

Funding: None

\section{Conflict of Interest: None}

\section{REFERENCES}

1. Alagappan P, Chellathurai A, Swaminathan TS, Mudali S, Kulasekaran N. Pentalogy of Cantrell. Indian J Radiol Imaging 2005;15(1):81.

2. Kheir AE, Bakhiet EA, Elhag SM, Karrar MZ. Pentalogy of Cantrell: case report and review of the literature. Sudanese J Paediatr 2014;14(1):85.

3. Wahab S, Sahoo B, Mittal S, Khan RA. Prenatal diagnosis of pentalogy of Cantrell in a case with craniorachischisis. Curr Pediatr Res 2017;21:8-10.

4. Mendaluk T, Mościcka A, Mroziński B, Szymankiewicz M. The incomplete pentalogy of Cantrell-A case report. Pediatria Polska 2015;90(3):241-244.

5. National Organization for Rare Disorders (NORD); 2011. Pentalogy of Cantrell . rarediseases.org

6. Bilodi AK, Gangadhar MR. Gastroschsis associated with other anomalies - A case report. Int J Curr Res Rev 2012;04(18):171175 . 